\title{
Mid1p/anillin and the septation initiation network orchestrate contractile ring assembly for cytokinesis
}

\author{
Olivier Hachet and Viesturs Simanis ${ }^{1}$ \\ Cell Cycle Control Laboratory, Swiss Institute for Experimental Cancer Research (ISREC), School of Life Sciences, \\ Ecole Polytechnique Fédérale de Lausanne (EPFL), 1066 Epalinges s/Lausanne, Switzerland
}

\begin{abstract}
In both animal cells and fungi, cytokinesis proceeds via a contractile actomyosin ring (CAR). Many CAR components and regulators are evolutionarily conserved. In Schizosaccharomyces pombe, the spatial cue for cytokinesis is provided by Mid1p/Anillin, whereas temporal coordination is ensured by the septation initiation network (SIN). However, neither Mid1p nor the SIN is considered to be essential for CAR assembly per se. Here, using 4D imaging, we reveal an unanticipated, novel role for the SIN in CAR assembly. We demonstrate that CAR assembly involves three, genetically separable steps: establishment of a cortical network of CAR proteins, its lateral condensation, and finally, the formation of a homogeneous CAR. We show that SIN mutants fail to form a homogeneous CAR; we identify hypophosphorylation and recruitment of the conserved PCH-family protein Cdc15p to the CAR as critical steps requiring SIN function. Furthermore, we show that in the absence of Mid1p, CAR assembly proceeds via an actomyosin filament, rather than a cortical network of CAR proteins. This mode of assembly is totally dependent on SIN signaling, thereby demonstrating a direct role for the SIN in CAR formation. Taken together, these data establish that Mid1p and the SIN are the key regulators that orchestrate CAR assembly.
\end{abstract}

[Keywords: S. pombe; cytokinesis; septation initiation network; Midlp/anillin; contractile actomyosin ring]

Supplemental material is available at http://www.genesdev.org.

Received May 19, 2008; revised version accepted September 24, 2008.

The spatial and temporal coordination of cytokinesis with mitosis is a problem that all dividing eukaryotic cells must solve, if they are to ensure faithful transmission of the genome during cell division. The fission yeast Schizosaccharomyces pombe provides an excellent model for the study of cytokinesis in eukaryotic cells. $S$. pombe cells are rod-shaped, grow by elongation at their tips, and divide by medial fission. Both polarized growth and cytokinesis rely on the F-actin cytoskeleton, which undergoes major rearrangements during the cell cycle. In interphase, F-actin is organized in patches distributed at the growing end(s) and in cables along the longitudinal axis of the cell. At the onset of mitosis, F-actin patches disappear from the cell ends, and contractile actomyosin ring (CAR) assembly is initiated. At the end of mitosis, coincident with spindle breakdown, the CAR contracts concomitantly with the synthesis of the dividing cell wall, or division septum.

The spatial cue for cytokinesis is provided by the anillin-like protein Midlp (Chang et al. 1996; Sohrmann et al. 1996), the localization of which is dictated by the position of the interphase nucleus (Daga and Chang

${ }^{1}$ Corresponding author.

E-MAIL viesturs.simanis@epfl.ch; FAX 41-21-652-6933.

Article is online at http://www.genesdev.org/cgi/doi/10.1101/gad.1697208.
2005), and Pom1p (Bahler and Pringle 1998; Celton-Morizur et al. 2006; Padte et al. 2006). In interphase, Midlp shuttles between the nucleus and the adjacent cortex and accumulates predominantly in the nuclear compartment. At the onset of mitosis, Midlp is released from the nucleus and forms a broad cortical band that defines the site for recruitment of ring components (Paoletti and Chang 2000).

Assembly of the CAR occurs through the ordered recruitment of ring components (Wu et al. 2003). After Midlp, the proteins that are recruited first are type II myosin heavy and light chains (Myo2p, Cdc4p, and Rlc1p) (McCollum et al. 1995; Kitayama et al. 1997; Le Goff et al. 2000), followed by three regulators of actin dynamics: the IQGAP protein Rng2p (Eng et al. 1998), then the formin Cdc12p (Chang et al. 1997), and finally, the protein Cdc15p (Fankhauser et al. 1995), the founder of the "pombe Cdc15p homology" (PCH) family. Eventually, as actin polymerization occurs (Arai and Mabuchi 2002), the tropomyosin Cdc8p appears (Balasubramanian et al. 1992), followed by $\alpha$-actinin Ain 1p (Wu et al. 2001) and finally Myp2p (Bezanilla et al. 1997), just prior to contraction. In structural terms, CAR assembly is initiated by the formation of a centrally placed cortical network of ring components that condenses to a ring-like structure (Wu et al. 2006), which eventually matures to 
a uniform ring by homogenization of the distribution of ring components (Supplemental Fig. S2). At the ultrastructural level, electron microscopy revealed that the CAR is originally made of $\sim 2000$ actin filaments organized in two hemispheres of filaments of opposite directionality (Kamasaki et al. 2007). In late anaphase, just prior to contraction, the two populations of filaments combine, suggesting that this reorganization may account for ring contraction (Kamasaki et al. 2007).

The temporal coordination of mitosis and cytokinesis is mediated by the septation initiation network (SIN) (Gould and Simanis 1997; Simanis 2003; Wolfe and Gould 2005). The SIN is a network of protein kinases that associate with the spindle pole body (SPB; the yeast counterpart of the centrosome) via the scaffolding proteins Sid4p, Cdc11p, and Ppc89p (Krapp et al. 2001; Tomlin et al. 2002; Rosenberg et al. 2006). SIN signaling is regulated via the GTPase Spg1p (Schmidt et al. 1997; Balasubramanian et al. 1998) whose nucleotide status is regulated by the bipartite GAP Cdc16p-Byr4p (Furge et al. 1998). Concomitant with SPB separation, Spg1p activation triggers the recruitment of the Cdc7p kinase to the SPB (Fankhauser and Simanis 1994; Sohrmann et al. 1998; Cerutti and Simanis 1999). The signal is then transduced by the downstream kinases Sid1p and Sid2p and their associated subunits Cdc14p and Mob1p (Sparks et al. 1999; Guertin et al. 2000; Hou et al. 2000). Inactivation of the SIN results in multiple rounds of nuclear division without cytokinesis, whereas SIN hyperactivation leads to multiseptated cells (Minet et al. 1979; Fankhauser and Simanis 1994; Ohkura et al. 1995; Schmidt et al. 1997).

Previous studies have implicated the SIN in CAR maintenance and contraction (Mishra et al. 2004), as well as synthesis of the division septum (Jin et al. 2006). Since analysis of SIN mutants revealed that F-actin structures and CAR proteins are present in the medial region during mitosis (Marks et al. 1986; Fankhauser et al. 1993; Fankhauser and Simanis 1994; Schmidt et al. 1997; Balasubramanian et al. 1998; Sparks et al. 1999; Chang and Gould 2000; Guertin et al. 2000; Hou et al. 2000; Krapp et al. 2001; Tomlin et al. 2002), the SIN has not been considered to be involved directly in CAR assembly.

However, the observation that CAR assembly can be induced by overexpression of spg1 in interphase (Schmidt et al. 1997) generates a conundrum: If the SIN is not involved in CAR assembly, how can spg1 overexpression promote CAR and septum formation in interphase? This prompted us to examine carefully whether the SIN contributes to contractile ring assembly. In this study, we reveal a novel role for the SIN in completion of contractile ring assembly in mitosis and identify Cdc $15 p$ recruitment to the CAR as a critical step under the control of the SIN. Finally, we show that in the absence of Midlp activity, the formation of actomyosin structures and CARs entirely depends on SIN function. We conclude that the SIN and Midlp/anillin orchestrate CAR assembly.

\section{Results \\ Spg1p-induced CAR assembly in interphase depends on SIN signaling}

The presence of CAR proteins and F-actin structures in the medial region of SIN mutants during mitosis presents us with a paradox-if the SIN is not involved in the reorganization of F-actin to the medial region of the cell, how can Spglp activation induce CAR assembly in interphase? One possible explanation is that increased spg1 expression causes inappropriate activation of another GTPase-mediated signaling pathway that is independent of the SIN. We therefore examined whether the induction of ring assembly by Spglp activation requires other components of the SIN. Cells were arrested in interphase using either the $c d c 2-17$ mutant or treatment with hydroxyurea (HU). Ring assembly and septation were then induced either by spg1 overexpression (Schmidt et al. 1997) or by inactivation of the Spg1p GAP using the heat-sensitive mutant cdc16-116 (Minet et al. 1979; Cerutti and Simanis 1999). Following spg1 overexpression, interphasic rings were observed in $43.2 \%$ of cells $(n>300)$. We found that both early and late ring components such as Cdc15p (Fig. 1A), Rlclp (Fig. 1B), and Myp2p (Supplemental Fig. S1A-C) were recruited to the rings induced by Spglp activation. Consistent with the assembly of a functional CAR, ring contraction and septum deposition were also observed (Fig. 1A, arrowhead). We also observed that Sidlp-GFP, which is the latest SIN component to associate with the SPB in anaphase B (Supplemental Fig. S5J), was recruited to the SPB, indicating that spg1 overexpression generates a fully active SIN (Supplemental Fig. S5K).

We used this method to examine the dependency of Spglp-promoted ring assembly on other SIN components, beginning with the SIN kinases downstream from Spglp. We found that no rings were assembled in interphase cells $(n>300)$ if either Sid2p (Fig. 1A,B), Sid1p (Supplemental Fig. S1D,E), or Cdc7p (Fig. 1C) were inactivated, indicating that the core kinases of the SIN are essential for Spglp-induced ring assembly. Similar results were obtained using the cdc16-116 mutant to activate $\operatorname{Spg} 1 \mathrm{p}$ (Fig. 1B). Importantly, the overproduction of Spglp was not affected by inactivation of the SIN (Fig. 1G). Inactivation of the scaffold proteins Sid4p and Cdc11p, which are both necessary for the association of the SIN with the SPB, also prevented CAR assembly upon Spglp activation (Fig. 1E).

Next, we considered the possibility that, since the SIN is implicated in the formation of the division septum (Jin et al. 2006), it might promote CAR assembly indirectly, as a consequence of septum formation. We therefore activated the SIN in an interphase-arrested bgs1-191 mutant (also referred to as drc1-191), which cannot form a septum (Le Goff et al. 1999; Liu et al. 1999). We found that SIN-induced ring assembly still occurred, despite the inability to synthesize a septum (Fig. 1D) (rings were observed in $42.7 \%$ of cells, $n>300$ ). Previous studies have demonstrated that the Polo kinase Plolp is required for ring assembly (Ohkura et al. 1995) and SIN activation 
A $\operatorname{spg} 1 \mathrm{OE}$ in $\operatorname{cdc} 2-17$
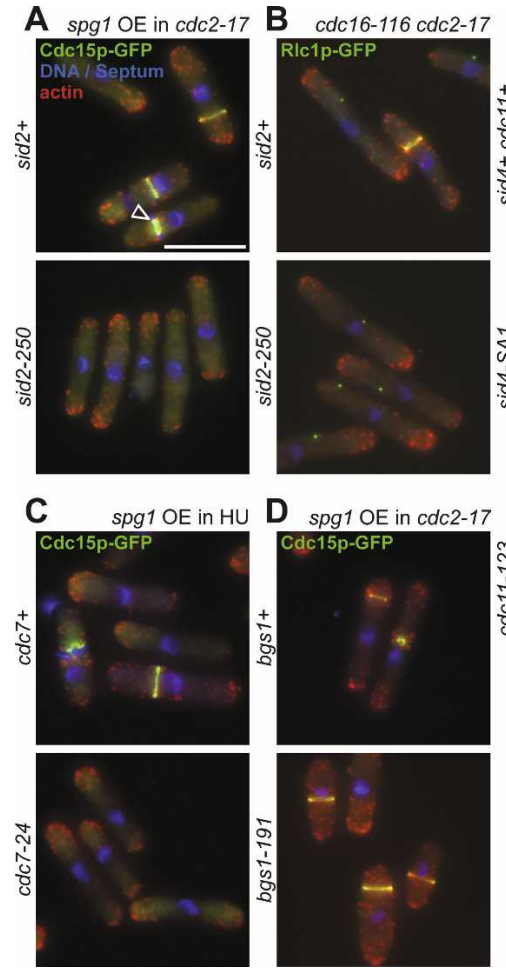

$\mathbf{F}$
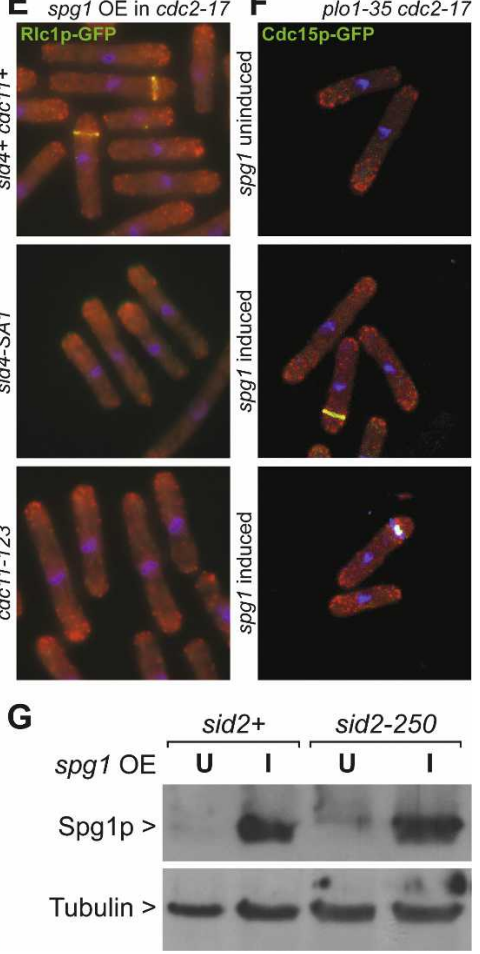

Figure 1. Spg1p-induced CAR assembly in interphase depends on SIN proteins. (A) Expression of spg1 was induced in $c d c 2-17 c d c 15-G F P$ (top) or $c d c 2-17$ sid2-250 cdc15-GFP cells (bottom), as described in the Materials and Methods. Cells were fixed and stained. The panels are a merge of DAPI-Calcofluor staining (DNA and septum, respectively, shown in blue), rhodamine-conjugated phalloidin (F-actin, shown in red), and Cdc15-GFP (shown in green). Note that Cdc15p-GFP staining is not seen that cell tips, as it does not survive the fixation conditions used. $(B) c d c 16-116$ cdc2-17 rlc1-GFP $($ top $)$ or cdc16-116 cdc2-17 sid2-250 rlc1-GFP cells (bottom) were synchronized by centrifugal elutriation and shifted for $2 \mathrm{~h} 30 \mathrm{~min}$ to $36^{\circ} \mathrm{C}$. Cells were fixed and stained as in $A$, except that green represent Rlclp-GFP. $(C)$ Expression of spg1 was induced in $c d c 15-G F P$ or $c d c 7-24$ cdc15-GFP cells for $22 \mathrm{~h}$ at $19^{\circ} \mathrm{C}$. HU was added to 12 $\mathrm{mM}$ for the last $5 \mathrm{~h}$ of the induction. This was followed by $2 \mathrm{~h} 30 \mathrm{~min}$ at $36^{\circ} \mathrm{C}$. The color scheme is the same as for $A$. (D) Expression of spg1 was induced in $c d c 2-17$ cdc15-GFP (top) orcdc2-17 bgs1-191 cdc15-GFP cells (bottom), as described in the Materials and Methods. Cells were fixed and stained. The color scheme is the same as for $A$. (E) Expression of spg1 was induced in cdc2-17 rlc1-GFP (top), cdc2-17 sid4-SA1 rlc1-GFP (middle), or cdc2-17 cdc11-123 rlc1-GFP cells (bottom), as described in the Materials and Methods. Cells were fixed and stained. The color scheme is the same as for $B$. $(F)$ Expression of spg1 was induced in $c d c 2-17$ plo1-35 cdc15-GFP cells as described in the Materials and Methods. Cells were fixed and stained. The top image shows uninduced cells, and the middle and bottom images show induced cells. The color scheme is the same as for $A$. (G) Western blot analysis showing that spg1 expression is unaffected in a sid2+ (left) compared with a sid2-250 background (right). Uninduced samples are shown in marked U lanes, while induced samples are shown in marked I lanes. Top and bottom panels show anti-Spglp and anti-Tubulin blots, respectively. Bar, $10 \mu \mathrm{m}$.

(Tanaka et al. 2001). Our data indicate that, in contrast to the core kinases of the SIN, Plolp is dispensable for Spglp-induced CAR assembly (Fig. 1F) (rings were observed in $45.1 \%$ of cells, $n>300$ ). This result is consistent with Plolp functioning upstream of Spglp in the SIN. Together, these results show that SIN signaling is required for CAR assembly induced by Spglp activation.

\section{The SIN is necessary to complete CAR assembly in mitosis}

The data presented above prompted us to examine whether the SIN plays a role in CAR assembly during mitosis. We examined wild-type and SIN mutant cells using 4D in vivo imaging and analyzed reconstructions of the CAR from sections across the middle of the cell. The myosin light chain Rlclp-GFP was used as a marker for the CAR, while mitotic progression was monitored using the SPB-associated protein Cdc11p-GFP.

Consistent with previous studies (Wu et al. 2006), analysis of wild-type cells revealed three major phases in CAR assembly (Fig. $2 \mathrm{~A}$ at $36^{\circ} \mathrm{C}$; Supplemental Fig. S2 at $25^{\circ} \mathrm{C}$ ). First, at the time of SPB separation (Fig. 2A, t1-t3; Supplemental Fig. S2A, t1-t4), the recruitment of Rlc1p at the cell center leads the formation of a broad cortical network of Rlclp particles around the nucleus (Fig. 2A, t4-5; Supplemental Fig. S2A, t4-10). Second, this broad network undergoes lateral condensation to form a discontinuous ring precursor (Fig. 2A, t5-t7; Supplemental Fig. S2A, t10-t14). Third, the maturation and consolidation of the ring precursor result in the formation of a homogeneous ring that persists until the end of anaphase B (Fig. 2A, t8-t16; Supplemental Fig. S2A, t15-t35) when it contracts (Fig. 2A, t16-35; Supplemental Fig. S2A, t35$60)$. These images were used as a reference for comparison with CAR assembly in SIN mutants. Analysis of spg1-B8 (Fig. 2, $n=105$ ), sid1-C14 (Supplemental Fig. S4, $n=10$ ), and sid2-250 (Supplemental Fig. S3, $n=80$ ) mutant cells showed that Rlclp-GFP particles were recruited to the medial region of the cell, and a ring precursor structure was formed. However, we observed that in SIN mutants the consolidation of the ring precursor into a homogeneous, closed ring was abnormal (Fig. 2B; Supplemental Figs. S3, S4). Discontinuous rings persisted beyond anaphase A (Fig. 2B, t7-t13) and then shrank and disassembled (Fig. 2B, t14-t20).

To evaluate ring heterogeneity in a quantitative manner, we calculated the standard deviation of the fluorescence intensity at the ring (SDFi) comparing data from wild-type and spg1-B8 mutant cells. SDFi was determined at four time points on each of 10 CARs (Fig. 3). The reconstructed rings (Fig. 3A,B) were divided into eight sectors (Fig. 3C), and the integrated intensity in each sector was measured using a threshold of $120 \%$ of 
Figure 2. Time-course analysis of ring assembly in mutants for the SIN and ring components. $(A-D)$ Cells of the indicated mutant genotype expressing Rlclp-GFP (ring marker) and Cdc1lp-GFP (SPB marker) were processed for live imaging at $36^{\circ} \mathrm{C}$ as described in the Materials and Methods. The frames shown were captured at 1-min intervals. The time courses have been aligned with respect to the frame showing maximal SPB distance $(\mathrm{t} 16$, gray box). Black bars at the bottom of the figure indicate the three phases of CAR assembly (see text for details). Bar, $10 \mu \mathrm{m}$.
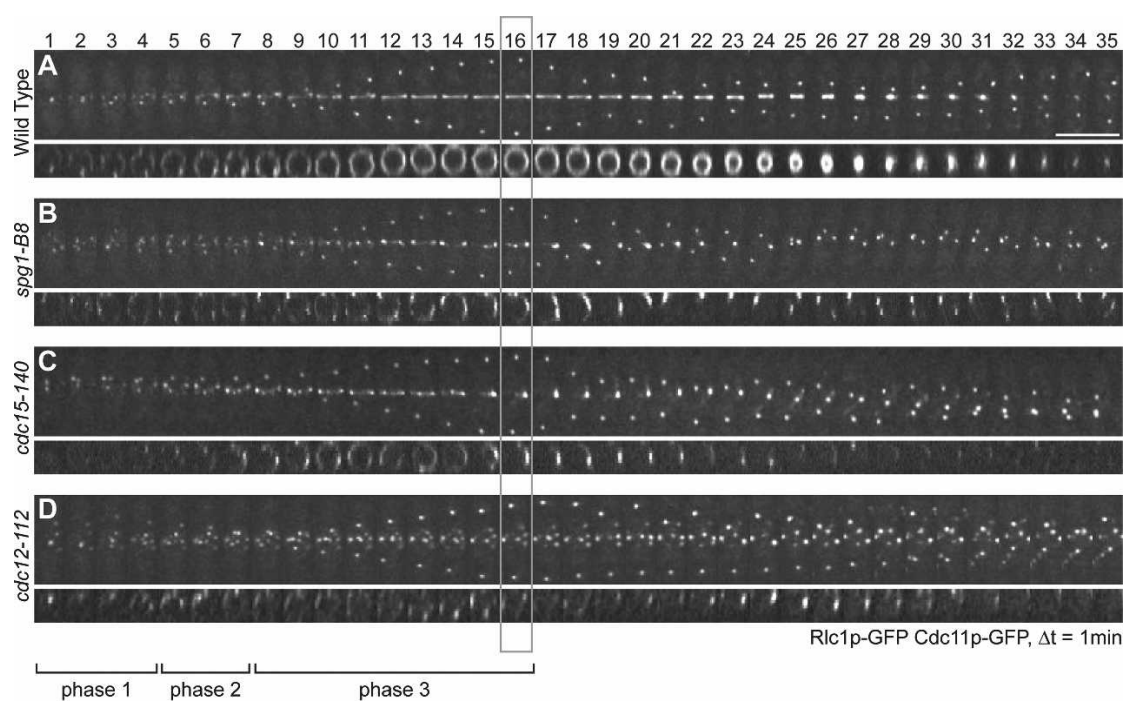

the background signal (Fig. 3C, red central square). In the wild type, the SDFi decreased progressively to reach $30 \%$ of the CAR's average fluorescence at the time of maximal SPB distance (maxSPBd) (Fig. 3D,E, blue line). In contrast, in the spg1-B8 mutant, the SDFi was, on average, higher compared with the wild type as ring assembly progressed, with a twofold difference 4 min before maxSPBd and a fourfold difference at the time of maxSPBd (125\% of the average fluorescence) (Fig. 3D,E, red line). Similar results were obtained in the sid2-250 mutant (Fig. 3E; Supplemental Fig. S3F,G, gray line). Taken together, these data establish that SIN signaling is required for the formation of a homogeneous ring structure.

It has been proposed that the SIN is required for CAR maintenance in cells in which the cytokinesis checkpoint is active (Mishra et al. 2004). Consistent with this study, analysis of fixed SIN bgs1-191 double-mutant cells revealed that the appearance of the CAR was aberrant, compared with that of the single bgs1-191 mutant (Supplemental Fig. S5; cf. A-D and E-H). To discriminate between a defect in CAR assembly or maintenance, we analyzed CAR assembly in the spg1-B8 bgs1-191 mutant by imaging of living cells (Supplemental Fig. S5I). Our data indicate clearly that the defective CAR in spg1-B8 bgs1-191 results from an assembly defect rather than a failure to maintain a properly assembled ring (Supplemental Fig. S5I). Together, these results establish that the SIN is necessary for the completion of CAR assembly in mitosis.

Next, we compared the effect of SIN inactivation on CAR assembly with that of mutants in components of the CAR. Cdc12p (formin) and Cdc15p (PCH family protein) are both involved in the control of actin cytoskeleton. They are essential constituents of the CAR and interact physically (Carnahan and Gould 2003). Examination of CAR assembly in the $c d c 12-112$ and $c d c 15-140$ mutants revealed an interesting difference between them. The $c d c 15-140$ mutant phenocopied the SIN mutants and failed to assemble a homogeneous CAR (Figs. 2C $[n=99$ ], 3E [green line]; Supplemental Fig. S4E,F). In contrast, Rlc1p remained dispersed in the cell center in the $c d c 12-112$ mutant (Fig. 2D, t5-t7, $n=109$ ), revealing a defect in the lateral condensation of the cortical network (Fig. 2D, t7-t35) in addition to the failure to form a homogeneous ring (Supplemental Fig. S4G,H). These data indicate that the principal steps of CAR assembly can be separated genetically.

\section{Cdc15p recruitment to the CAR requires the SIN}

The phenotypic similarity of cdc15-140 and SIN mutants, as well as the shared ability of Cdc15p and Spg1p to trigger F-actin rearrangement when overproduced in interphase (Fankhauser et al. 1995; Schmidt et al. 1997), led us to consider Cdc15p recruitment as a possible candidate for the SIN-dependent step in CAR assembly. First, we assessed the influence of SIN signaling on Cdc15p localization. In wild-type cells, Cdc15p-GFP (Carnahan and Gould 2003) was observed as patches at the cell tips in addition to a substantial diffuse cytoplasmic signal (Fig. 4A, t1). Upon entry into mitosis, the patches disappeared from the cell tips (Fig. 4A, t1-t9), simultaneously with the appearance of Cdc15p-GFP at the cell center (Fig. 4A, t4-t9). The intensity of the cytoplasmic Cdc15p-GFP signal decreased as the ring signal became more intense, consistent with progressive depletion of Cdc15p-GFP from the cytoplasm as it is recruited to the CAR (Fig. 4A [t8-t14], C).

In contrast, in the sid2-250 mutant, Cdc15p-GFP patches remained at the cell tips even during mitosis (Fig. 4B), and the cytoplasmic signal did not vary significantly (Fig. 4B,C). Although some Cdc15p-GFP was observed at the medial region of the cell (Fig. 4B, t4-t35), recruitment of Cdc15p-GFP to the CAR was severely compromised (Fig. 4B, t8-t35). These observations demonstrate that a functional SIN is required for recruitment of Cdc15p to the CAR in mitosis. Furthermore, they also indicate that the ring structure formed in SIN mutants is not only defective in its morphology but also in its composition. 

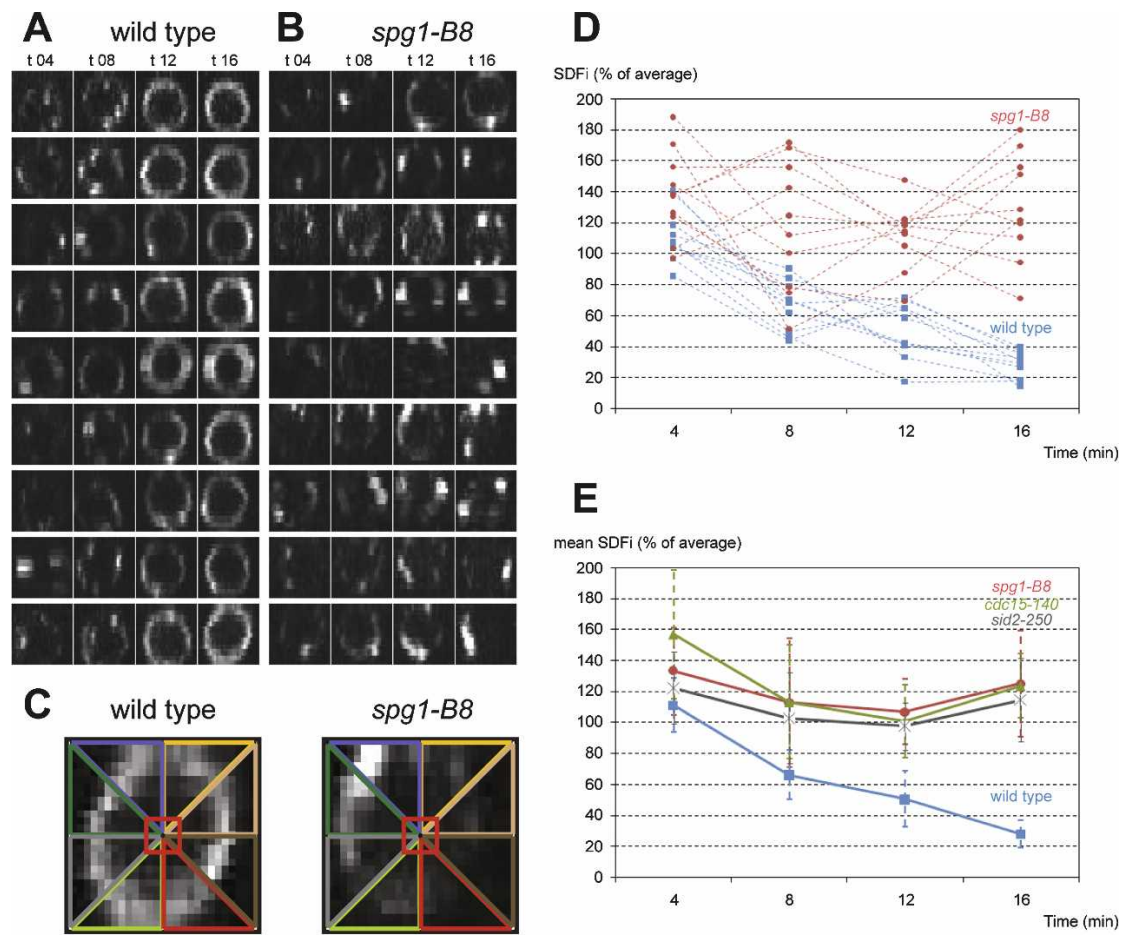

Figure 3. Analysis of CAR homogeneity in wild type and SIN mutants. $(A, B)$ Ten cells from wild type $(A)$ and $\operatorname{spg} 1-B 8(B)$ were analyzed; rings were reconstructed at four time points as indicated; t16 represents the time of maxSPBd (see Fig. 2). (C) The reconstructed rings were divided into eight sectors as shown in the diagram for SDFi calculation. The red square shown in the center of the diagram was used to determine the background intensity to set the quantification threshold. (D) The graph represents the ratio of the SDFi to the mean fluorescence intensity of individual cells over time. Blue lines correspond to wild type cells, and red lines correspond to spg1-B8 mutant cells. $(E)$ The graph represents the mean SDFi, the blue line corresponds to wild-type cells $(n=10)$, the red line corresponds to spg1- $B 8 \mathrm{mu}$ tant cells $(n=10)$, the green line corresponds to $c d c 15-140$ mutant cells $(n=10)$, and the gray line corresponds to sid2-250 mutant cells $(n=5)$.

Cdc15p is a phosphoprotein, whose phosphorylation state changes during the cell cycle. Previous studies have shown that the hypophosphorylated form of Cdc15p predominates during CAR formation in mitosis (Fankhauser et al. 1995). We therefore used the assay for ectopic ring assembly in interphase to investigate whether the activity of the SIN affects Cdc15p phosphorylation. $c d c 16-116$ cells expressing Cdc15p-HA were arrested in interphase and shifted at $36^{\circ} \mathrm{C}$ to activate the SIN. This resulted in a faster migration of Cdc $15 p-H A$ compared with the unshifted control (Fig. 4D, left panel) or to a $c d c 16^{+}$control at $36^{\circ} \mathrm{C}$ (Fig. $4 \mathrm{D}$, right panel). These data imply that SIN activation is sufficient to promote the accumulation of Cdc15p-HA in its hypophosphorylated form.

\section{SIN activation triggers CAR assembly independently of Mid1p/anillin}

When examining the interphasic CARs induced by spg 1 overexpression, we were struck by the fact that they were frequently misplaced and/or misoriented (Fig. 5A,B, arrowheads). Quantitation revealed that in contrast to rings that form during mitosis, which are restricted to the middle of the cell, a majority of Spglp-induced rings were eccentrically placed $(68 \%, n=117)$ (Fig. 5C). Furthermore, a significant proportion of rings were not orthogonal to the long axis of the cell $(19 \%, n=117)$ (Fig. 5C). This phenotype is reminiscent of that of an mid1 mutant (Chang et al. 1996; Sohrmann et al. 1996). Therefore, we examined the effect upon ring positioning by inactivating mid1 in cells overexpressing spg1. We found that Spg1p-induced rings formed in the mid1-6 mutant and that their distribution was similar in absence or presence of mid1 function (Fig. 5C), indicating that the Midlp spatial cue is dispensable for their formation. Consistent with this, immunostaining revealed that Midlp was never associated with Spglp-induced ectopically positioned rings (regions $B$ and $C_{;} n=25$ ) and remained predominantly nuclear (Fig. 5D,E). However, Midlp was observed in $\sim 50 \%$ of the rings that formed proximal to the nucleus (region A; $n=15$ ) (Fig. 5E), indicating that Midlp can still shuttle between the nucleus and the adjacent cell cortex when the SIN is active.

The properties of SIN-induced rings are similar to those of CARs formed in the absence of midl function

Since CAR formation induced by SIN activation in interphase bypasses the Midlp spatial cue, we used live imaging to examine how the CAR was assembled in this context. In contrast to the situation in a normal mitosis (Fig. 6A), we observed that the CAR assembled from an extended filamentous structure composed of ring components such as Rlc1p (Fig. 6B), Cdc15p (data not shown), and F-actin (Supplemental Fig. S1H) that eventually formed a ring (Fig. 6B; Supplemental Movie S1). This assembly process therefore occurs without the establishment of a centrally placed cortical network of ring components. We also observed that SIN-induced rings contracted more slowly compared with rings formed in wildtype cells (Fig. 6E), indicating that rings formed from an actomyosin filament function less efficiently.

These data led us to examine the process of CAR assembly in a mid1-6 mutant, where the spatial cue for 
Figure 4. The SIN is required for recruitment of Cdc15p to the CAR. $(A, B)$ Live imaging was performed at $36^{\circ} \mathrm{C}$ on cells expressing Cdc15p-GFP and Cdc11p-GFP in wild type $(A)$ and the sid2-250 mutant $(B) .(C)$ The graph represents the cytoplasmic fluorescence relative to the extracellular background in wild-type (black squares) and sid2-250 mutant cells (white circles). (D) Western blot analysis of Cdc15p-HA (top panel) and Tubulin (bottom panel). The left panel shows extracts from $c d c 16-116$ cells at the indicated temperature arrested with HU. The right panel shows extracts from $c d c 2-17$ cells and cdc16-116 cdc2-17 double-mutant cells arrested in $\mathrm{G} 2$ at $36^{\circ} \mathrm{C}$. Bar, $10 \mu \mathrm{m}$.

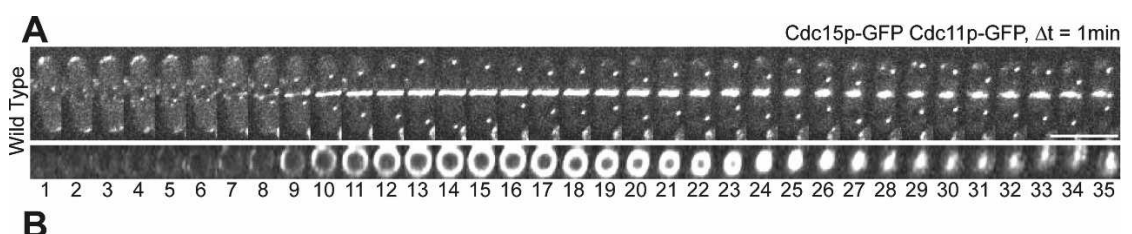

B

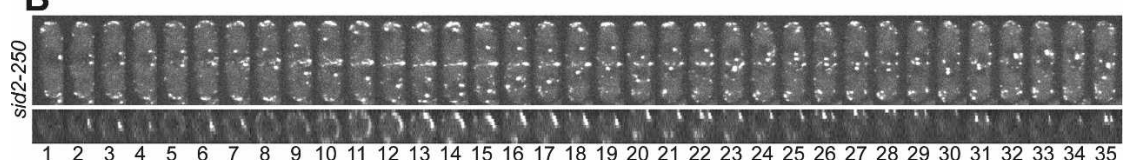

C

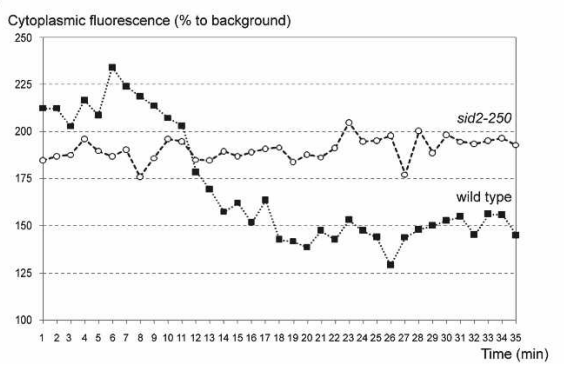

D

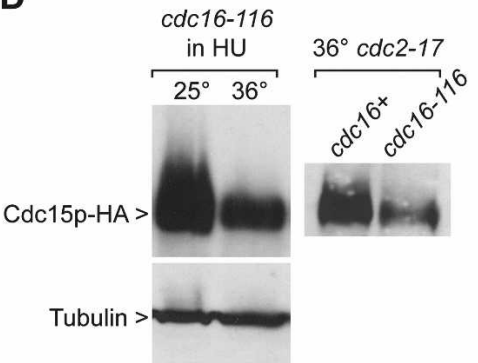

ring formation is absent but SIN signaling is normal. We observed that CAR assembly in a mid1 mutant (Fig. 6C) and in mid1s (Fig. 6D) also proceeds via a filamentous actomyosin structure, resembling that produced by activation of the SIN in interphase (Fig. 6B), which is consistent with previous observations of Myo2p recruitment to the CAR in the absence of Midlp (Motegi et al. 2004). Furthermore, our data show that the rings formed in the absence of mid1 function contracted with similar kinetics to those formed by induction of the SIN (Fig. 6 E). These observations support the view that ring assembly induced by SIN activation in interphase occurs independently of Mid1p.

\section{Mid1p/anillin and the SIN cooperate to mediate CAR assembly}

The similarity of the mechanisms of CAR assembly following SIN activation in interphase and in the absence of mid1 function prompted us to test whether ring assembly in the mid1 mutant relies on SIN signaling. Analysis of ring formation in a mid1-6 sid2-250 double mutant revealed that the formation of both the extended actomyosin filament and the CAR in mitosis was completely abolished (Fig. 7A-D). This implies that the assembly of actomyosin structures in the absence of mid1 function entirely relies on SIN signaling and provides evidence for a direct role of the SIN in CAR assembly. Together these results demonstrate that Mid1p and the SIN cooperate to orchestrate CAR assembly in mitosis.

Previous studies have shown that Plolp is required for activation of the SIN (Tanaka et al. 2001); furthermore, Plolp regulates the phosphorylation state of Midlp and its release from the nucleus (Bahler et al. 1998; MacIver et al. 2003a). This raises the possibility that Plolp could coordinate Midlp and the SIN. To test this, we examined
CAR formation in the separation-of-function plo1-ts18 allele, which is primarily defective in the regulation of Midlp and positioning of the division septum (MacIver et al. 2003a). We observed that the CAR assembled via an extended actomyosin filament in the plo1-ts18 mutant; in contrast, no CAR was formed in the spg1-B8 plo1-ts18 mutant (Fig. 7E). Increased expression of plo1 can induce CAR and septum formation (Ohkura et al. 1995). We used overexpression of the constitutively active plo1-con allele (MacIver et al. 2003b) to determine whether plo1 could induce ring formation in the absence of SIN function. We found that plo1-con expression in sid2-250 induced the formation of nonhomogeneous, defective rings (Fig. 7F) resembling those observed in sid2-250 (Fig. 7B). It is likely that the formation of these actomyosin structures result from the activation of Midlp by plo1con. These data support the notion that Plolp coordinates Midlp and the SIN to orchestrate CAR assembly (Fig. 8E).

\section{Discussion}

\section{The SIN is necessary for CAR assembly in mitosis}

In this study, we provided clear evidence that reveals a novel role for the SIN in the process of contractile ring assembly in mitosis, as the cell prepares for cytokinesis. In vivo analysis of CAR assembly in SIN mutants has revealed that CAR assembly does not proceed beyond the stage of lateral condensation of the broad cortical network of ring components and results in an incompletely formed ring precursor structure (Fig. 8D). Therefore, the SIN is required both to generate the CAR in the early stages of mitosis and, subsequently, to trigger septum formation at the end of mitosis. Our results are consistent with the observation that $\operatorname{sepH}$, the or- 

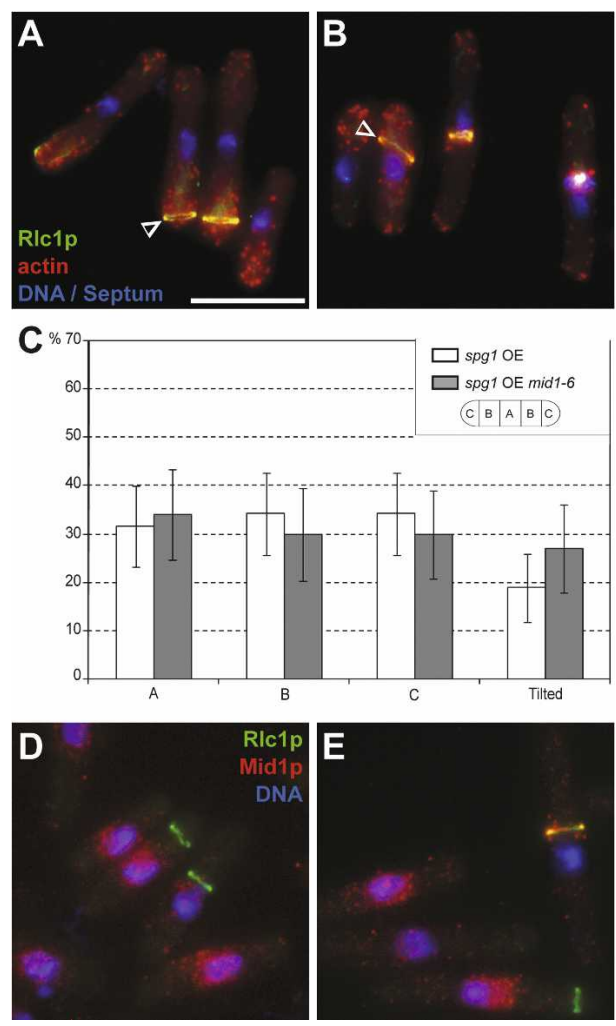

Figure 5. Spglp activation in interphase triggers Mid1p-independent CAR assembly. cdc2-17 rlc1-GFP cells were arrested in G2, and expression of $\operatorname{spg} 1$ was induced as described in Materials and Methods. Cells were then fixed and analyzed. $(A, B)$ The image shows the Rlclp-GFP protein (green), DNA stained with DAPI (blue), the septum stained with Calcofluor (blue), and Factin stained with rhodamine-conjugated phalloidin (red). The arrowheads indicate mispositioned and misoriented or tilted rings. $(C)$ Graphical representation of ectopic ring distribution, where $\mathrm{A}, \mathrm{B}$, and $\mathrm{C}$ correspond to the cell areas described in the diagram in the top right corner. The proportion of misoriented rings is represented in the column entitled "Tilted." $(D, E)$ spg1 expression was induced as described above, and cells were fixed and stained with an anti-Midlp antibody (red), and DAPI (blue); Rlclp-GFP is shown in green. Bar, $10 \mu \mathrm{m}$.

tholog of $c d c 7$ in Aspergillus nidulans, is required for formation of the F-actin ring (Bruno et al. 2001).

It is interesting to note that the ring structure that forms in SIN mutants seems to disassemble by progressive shortening, as if by contraction, suggesting that these defective rings may have some contractile properties despite their aberrant organization and composition. Analysis of the CAR in early mitosis using electron microscopy has demonstrated that it is composed of F-actin filaments that are sorted into two distinct populations of opposite polarity (Kamasaki et al. 2007). Future studies should clarify whether this organization is established correctly in SIN mutants.

Recent studies have produced apparently conflicting models for CAR assembly in fission yeast; a leading cable mechanism, whereby cables emanate from a single nucleation site, and a search/capture mechanism that proceeds via the formation of a network of nodes that coalesce to form a CAR (for a detailed discussion of this topic, see Mishra and Oliferenko 2008). Our results indicate that, depending on whether the Midlp spatial cue is present, either mechanism can be used to form a functional CAR. However, it appears that the CARs formed by what resembles the "leading cable" mechanism independently of Midlp contract more slowly. It will be interesting to determine whether any components are missing, or inappropriately regulated in the absence of Midlp. In this context, it is noteworthy that Clplp/ Flplp, which is important to assure stability of the CAR, is recruited to the CAR by Midlp (Clifford et al. 2008).

Our data point to recruitment of the $\mathrm{PCH}$ protein Cdc15p as an important, SIN-dependent step in CAR assembly. Previous studies have shown that Cdc15p is dephosphorylated at the time of its recruitment to the CAR (Fankhauser et al. 1995; Wachtler et al. 2006). The formation of ectopic rings in interphase cells as a result of SIN activation is accompanied by the accumulation of hypophosphorylated Cdc15p. It is not known whether dephosphorylation of Cdc15p is the trigger for Cdc15p to associate with the CAR, or whether this is a consequence of the presence of phosphoprotein phosphatases such as Clp1p at the CAR (Wachtler et al. 2006; Clifford et al. 2008). It is tempting to speculate that one early mitotic function of the SIN may be to regulate the activity of the phosphatase(s) that dephosphorylate Cdc15p and other CAR components such as Myo2p (Motegi et al. 2004). Identification of SIN targets in CAR proteins and regulators of CAR assembly will clearly be of interest.

Why would inefficient recruitment of Cdc15p perturb CAR assembly? Previous studies have established that the PCH-family protein Cdc15p interacts with Formin/ Cdc12p and Myo1, an activator of the Arp2/3 complex, both of which control actin polymerization (Carnahan and Gould 2003). It is therefore possible that absence of Cdc15p alters the polymerization rates of actin by affecting the activity of Cdc12p/Formin and/or Arp2/3 activity. Computer modeling of CAR assembly (Vavylonis et al. 2008) predicts that perturbation of the actin polymerization rate would result in the clumping of ring components, which resembles what we observed in $c d c 15$ and SIN mutants. It has been reported that overexpression of cdc15 is sufficient to induce the formation of filamentous actomyosin structures and CARs (Supplemental Fig. S1G; Fankhauser et al. 1995). In other organisms, $\mathrm{PCH}$ protein overexpression also leads to the formation of large actin cables, indicative of an actin filament bundling activity (Spencer et al. 1997; Chitu et al. 2005). It is therefore possible that Cdc15p act as an actin bundling factor that contributes to the proper organization of the CAR.

\section{Implications for SIN function and activity}

The results of numerous studies of the localization and activity of SIN proteins during the cell cycle in wild-type and mutant cells have led to the model that the SIN becomes active in late anaphase B. The transition of SIN 
Hachet and Simanis

Figure 6. Live imaging analysis of SINinduced CAR assembly and in the absence of Midlp activity. $(A-D)$ Cells expressing Rlclp-GFP were filmed as they progressed through mitosis and cytokinesis at $36^{\circ} \mathrm{C}$. $A$ Shows a wild-type cell going through normal mitosis, $B$ shows a $c d c 2-17$ interphase-arrested cell overexpressing spg1, $C$ shows a mid1-6 mutant cell in mitosis, and $D$ shows a mid1D-null mutant cell in mitosis. Bar, $10 \mu \mathrm{m}$. (E) Synchronous cultures of wild-type, $c d c 2-17 c d c 16-116$, and mid1-6 cells expressing Rlc1p-GFP were generated by centrifugal elutriation and filmed in yeast extract medium at $36^{\circ} \mathrm{C}$ to calculate the average CAR contraction time represented in this graph.
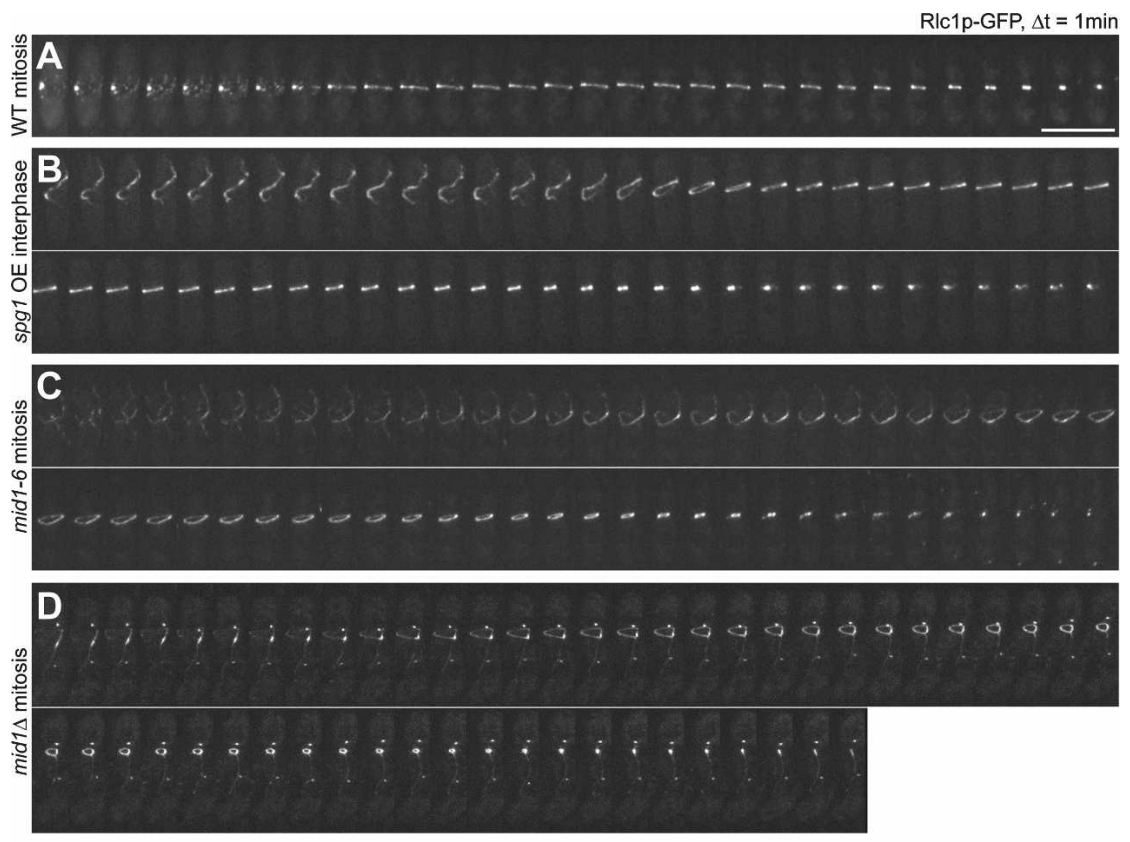

$\mathbf{E}$

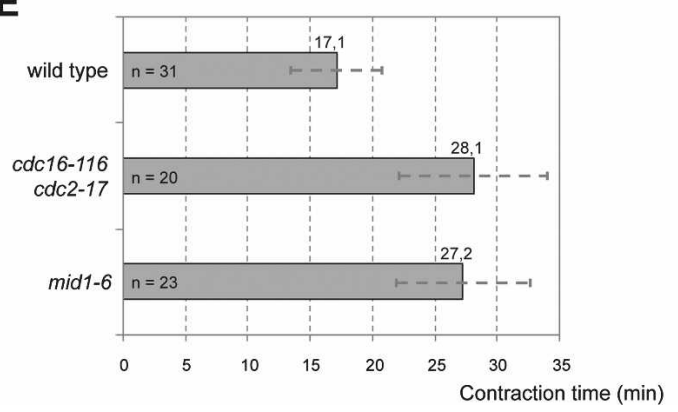

proteins from both SPBs in early mitosis to an asymmetric distribution of Cdc7p and Sidlp on the new SPB in anaphase $\mathrm{B}$, together with the appearance of Sid2pMoblp at the CAR at the time of its contraction, have been assumed to represent a marker for activation of the SIN (for review, see Simanis 2003; Krapp et al. 2004; Wolfe and Gould 2005). The data presented in this study reveal an active role for the SIN, during ring formation in metaphase and anaphase A, before the asymmetry of SIN proteins is established. This implies that Cdc7p and Sidlp asymmetric distribution and Sid2p-Moblp recruitment at the CAR may not constitute the only indicators of SIN activity, and therefore require that this model be modified.

In metaphase and anaphase A, Cdc7p, Spg1-GTP, Sid2p, and Mob1p are present on both the SPBs, but Sidlp-Cdc14p is not. This may represent a visual manifestation of the configuration of the SIN required for CAR assembly. Whether the early mitotic role of the SIN is executed in the cytoplasm, at the SPB, or both, is unclear, but the requirement for the Cdc11p-Sid4p scaffold for CAR formation suggests that the SIN proteins must transit via the SPB, perhaps to be activated. The failure to form a CAR in a sid1 mutant suggests that Sidlp is also required for the early function of the SIN, although maybe not at the SPB. Consistent with a role for the SIN early in mitosis, analysis of the kinase activity of Sid2p showed that although it peaks at the time of CAR constriction, significant activity is already present in early mitotic cells (Sparks et al. 1999). The early mitotic configuration of the SIN is clearly distinct from that of anaphase B, in that the steady-state level of Sidlp at the SPB is very low (or absent) in early mitosis. Thus, the arrival of Sidlp at the new SPB may represent a remodeling of the SIN activity to permit septum formation using the fully formed, mature CAR. Analysis of SIN protein complexes through mitosis should resolve how the early and late mitotic activities of the SIN differ.

The equatorial microtubule organizing center (EMTOC), which gives rise to the post-anaphase microtubule array at the end of mitosis, forms at the site of the CAR. A study of the EMTOC has suggested that the SIN is required for its formation (Heitz et al. 2001). While it remains possible that this is the case, the formation of a fragile ring in SIN mutants may also contribute to the failure to form a functional EMTOC. Future studies that inactivate the SIN punctually during anaphase will be required to resolve the role of the SIN in EMTOC formation. 

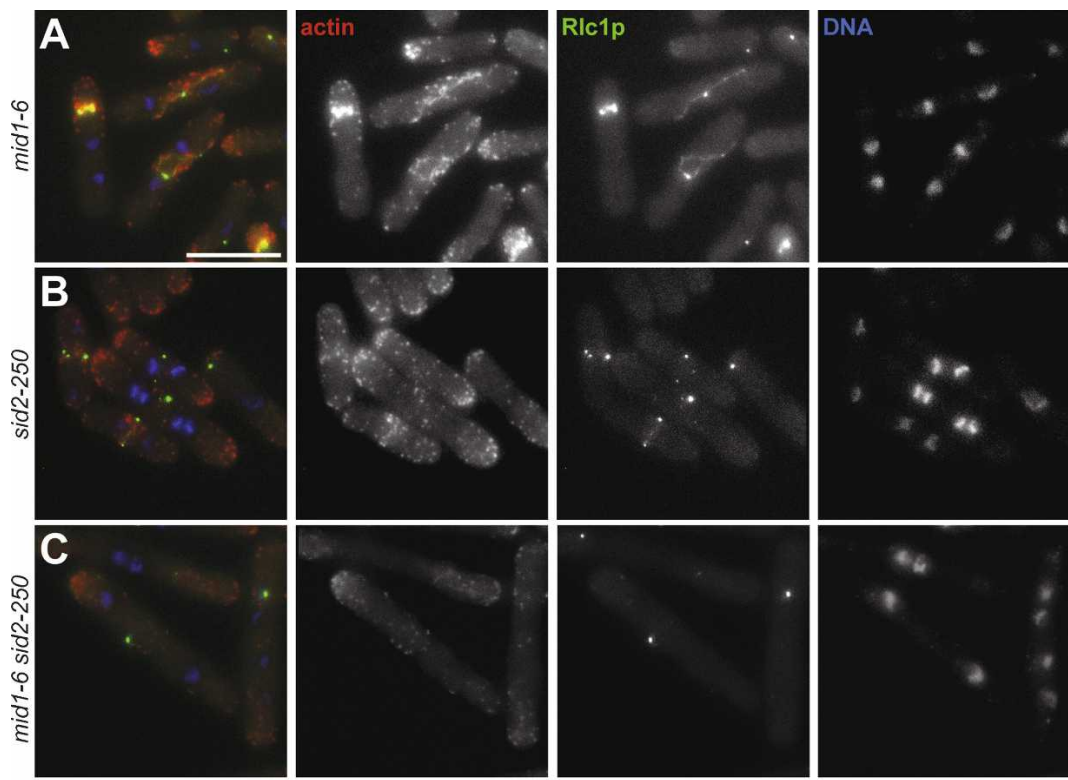

D

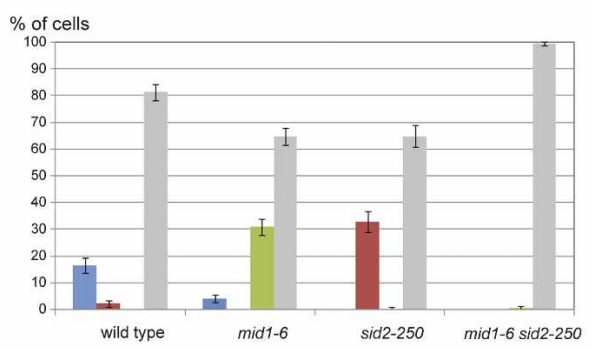

E

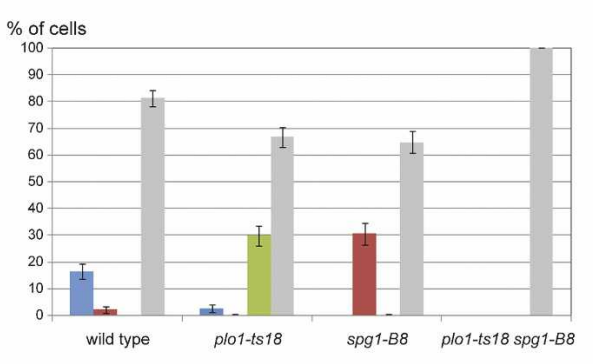

$\mathbf{F}$

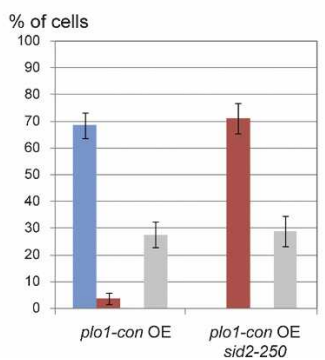

Figure 7. Ring assembly depends on SIN signaling in the absence of Midlp activity. $(A-C)$ Cells of the indicated genotypes were fixed and stained after shifting an exponentially growing population of cells for $3 \mathrm{~h}$ from $25^{\circ} \mathrm{C}$ to $36^{\circ} \mathrm{C}$. F-actin is shown in red, Rcllp-GFP is shown in green, and DNA is shown in blue in the merge; the corresponding grayscale panels for each channel are also shown. A shows mid1-6 mutant cells, $B$ shows sid2-250 mutant cells, and $C$ shows mid1-6 sid2-250 double-mutant cells. $(D-F)$ Graphical representations of quantification of the phenotypes observed are shown; blue bars represent the percentage of cells with a normal ring or septum, red bars represent the percentage of cells with a defective nonhomogeneous ring, green bars represent the percentage of cells with an actomyosin filament, and gray bars represent the percentage of cells with an Rlc1p-GFP dot. $(D, E)$ Cells of the indicated genotype were shifted for $3 \mathrm{~h}$ at $36^{\circ} \mathrm{C}$. $(F)$ Overexpression of plo1-con was induced for $16 \mathrm{~h}$ at $25^{\circ} \mathrm{C}$ followed by a $2 \mathrm{~h} 30 \mathrm{~min}$ shift at $36^{\circ} \mathrm{C}$ in wild-type or sid2-250 cells expressing RlclpGFP. Bar, $10 \mu \mathrm{m}$.
Cooperation of Mid1p/anillin and the SIN during CAR assembly

Our data show that CAR assembly induced by activation of the SIN in interphase bypasses the spatial cue provided by the anillin-related protein Midlp. In this case, as in mid1 mutants, the ring forms from a filamentous structure, rather than a cortical network of ring components (Fig. 8B). This indicates that the formation of a broad cortical network is not essential for ring assembly. The observation that in the absence of mid1 and SIN function both the assembly of the filamentous actomyosin structure and of the actomyosin cortical network is abolished demonstrates that assembly of actomyosin structures can be triggered by two independent mechanisms: Midlp release from the nucleus and SIN signaling.

It is possible that SIN activity induces the formation of a filamentous actomyosin structure by promoting the recruitment of Cdc15p to F-actin. Alternatively, SIN signaling may enhance the rate of actin polymerization. In SIN mutants, the accumulation of CAR proteins at the medial region in response to the Midlp/anillin cue may provide a sufficient concentration of CAR components to permit the early stages of CAR assembly. However, inefficient recruitment of Cdc15p (and perhaps other CAR proteins) then precludes the formation of a homogeneous CAR. The failure to form any CAR-like structure in the mid1 SIN double mutants may then be because, in the absence of a spatial cue, the local concentration of CAR components at any point on the cortex is too low to permit efficient filament assembly in the absence of SIN function. Computer modeling of these situations will be of considerable interest (Vavylonis et al. 2008).

Since Midlp shuttles between the nucleus and the cy- 
A

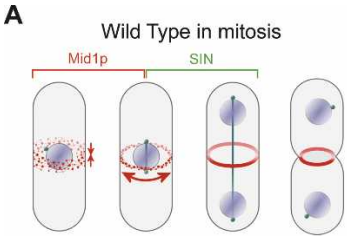

C

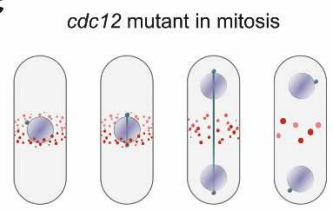

$\mathbf{E}$

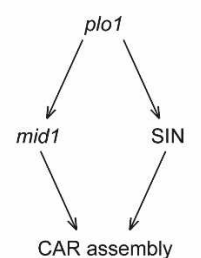

B

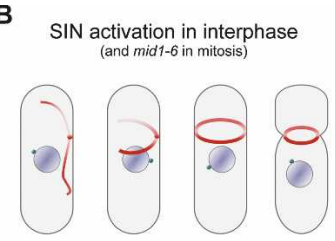

D

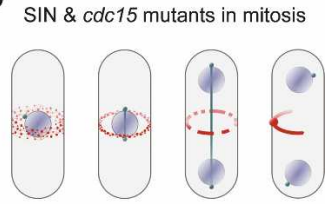

Figure 8. Models for contractile ring assembly. Models recapitulating the three phases of contractile ring assembly in situations described in this study. (A) In wild-type mitosis, ring assembly is initiated by the formation of a cortical network of ring components that undergoes lateral condensation, giving rise to a nonhomogeneous ring precursor. This structure eventually matures by recruitment of additional factors such as Cdc15p, displaying the uniform distribution of ring components distribution that characterizes a functional ring. $(B)$ When the SIN is activated in interphase, ring assembly is initiated by the formation of a Midlp-independent filamentous actomyosin structure that eventually forms a ring structure. This structure is then competent for contraction, although it contracts more slowly. This mode of assembly is also observed in mid1 mutants in mitosis. $(C)$ In a $c d c 12$ mutant, ring assembly is initiated correctly in that it allows for the formation of a cortical network; however, this network fails to coalesce by lateral condensation and instead remains loose. (D) In SIN and cdc15 mutants, ring assembly proceeds correctly until lateral condensation of the cortical network. Thereafter, the ring precursor fails to mature, remains nonuniform, showing gaps and clumps of ring components, and, in the case of SIN mutants, fails to recruit Cdc15p. Finally, the defective rings seem to collapse, perhaps by a process involving contraction. (E) Model for the coordination of CAR assembly by plo1 controlling the two key regulators mid1 and the SIN. The SIN and Mid1p are both important for assembly of a functional CAR and cooperate to effect this. Regulation of both by Plolp provides an attractive means of orchestrating CAR assembly during mitosis.

toplasm (Paoletti and Chang 2000), why does septum ring formation resulting from activation of the SIN in interphase not use the spatial cue that should be available in the cytoplasm? We do not have a complete answer to this question, but we consider two possibilities below. First, the remodeled anaphase B form of the SIN may preclude cytoplasmic retention/CAR association of Midlp. In this context, it is noteworthy that Midlp dissociates from the CAR just prior to its contraction (Sohrmann et al. 1996), at a time that coincides with the

appearance of Sid2p-Moblp at the CAR; future studies will address whether removal of Midlp from the CAR is a manifestation of the anaphase $B$ configuration of the SIN.

Alternatively, it may result from the fact that the rings are being induced in interphase cells. It has been established that the core elements of the SIN are genetically downstream from plo1 (Tanaka et al. 2001) and that Plolp activity is required for Midlp to leave the nucleus (Bahler et al. 1998). Thus, ectopic activation of the SIN at the level of Spglp in interphase bypasses the normal requirement for Plolp to activate the SIN. However, since in interphase cells Plolp is not activated, Midlp remains predominantly nuclear. This is consistent with our finding that no CAR is formed in a SIN plo1-ts18 double mutant, despite the presence of functional Midlp in the cell. In this context, it is also noteworthy that none of the rings formed at the extremities of the cell have Midlp associated with them, while about half of the rings that form proximal to the nucleus show a Midlp signal (Fig. 5). In these cases, it is possible that Midlp from the cortical fraction overlying the interphase nucleus becomes incorporated into the nascent ring.

Our study shows that CAR assembly in fission yeast is actually controlled by two independent cooperating key regulators: Midl and the SIN, both of which were previously considered not to be involved in this process. These two regulators are partially redundant for the assembly of actomyosin structures, yet each has a specific role: Mid1p ensures correct CAR positioning, while the SIN ensures the formation of a functional CAR. In higher eukaryotes, recent studies have revealed that polo-family proteins regulate multiple events during cytokinesis, including organization of the spindle midzone and regulating Rho-GEF proteins (for a review, see Petronczki et al. 2008). The fact that Plolp is required both to activate the SIN and to promote the release of Midlp from the nucleus provides an excellent way to coordinate these two regulators.

\section{Materials and methods}

Standard techniques were used for growth and manipulation of S. pombe cells (Moreno et al. 1991). Cells were grown in yeast extract (YE) or EMM2 minimal medium, supplemented as required. Elutriations were performed using a Beckman JS 5.0 system.

To assay for induction of ectopic ring assembly in interphase cells, spg1 expression was induced from an nmt1-spg1 expression cassette integrated at the leu1 locus (Schmidt et al. 1997) by inducing for $22 \mathrm{~h}$ at $19^{\circ} \mathrm{C}$ in minimal medium without thiamine. Cells were then shifted for $2 \mathrm{~h} 30 \mathrm{~min}$ to $36^{\circ} \mathrm{C}$ to inactivate $c d c 2-17$ and then fixed and analyzed. The same procedure was used to overexpress $c d c 15$. When $c d c 16-116$ was used for activation of Spglp-dependent signaling in $c d c 2-17$-arrested cells, small G2 cells were selected by centrifugal elutriation and then incubated for $2 \mathrm{~h} 30 \mathrm{~min}$ at $36^{\circ} \mathrm{C}$ to simultaneously inactivate $c d c 16-116$ and $c d c 2-17$. When HU treatment was used to synchronize cells, they were incubated for $4 \mathrm{~h}$ at $25^{\circ} \mathrm{C}$ in the presence of $12 \mathrm{mM}$ HU before shifting the culture for $2 \mathrm{~h} 30 \mathrm{~min}$ to $36^{\circ} \mathrm{C}$. 


\section{Image capture and analysis}

Cells were fixed for $5 \mathrm{~min}$ by addition of formaldehyde to $4 \%$ $(\mathrm{v} / \mathrm{v})$ to the culture medium. After two PBS washes, cells were permeabilized by treatment with PBS containing $1 \%(\mathrm{v} / \mathrm{v}) \mathrm{NP}-$ 40 for $20 \mathrm{~min}$. After washing in PBS, cells were stained with 30 $\mathrm{U} / \mathrm{mL}$ rhodamine-conjugated phalloidin, $0.8 \mu \mathrm{g} / \mathrm{mL}$ DAPI, and 3 $\mu \mathrm{g} / \mathrm{mL}$ Calcofluor. Immunostaining for Midl $\mathrm{p}$ was performed as described previously (Sohrmann et al. 1996). Fixed samples were imaged using an inverted Till Olympus IX70 microscope equipped with a 100×/1.4 Plan Apochromat objective and Metamorph acquisition software except for the plo1-35 experiment, where a Leica TCS SP2 confocal microscope was used.

For imaging of living cells, cultures were synchronized by elutriation, and cells were concentrated by filtration to minimize stress. Cells were then deposited on a $1 \%$ agarose pad containing growth medium, mounted between sealed slide and coverslip, and allowed to recover for $30-45 \mathrm{~min}$ at $36^{\circ} \mathrm{C}$. Samples were then imaged by spinning disk time lapse microscopy using a 63×/1.4 Plan Apochromat objective on an inverted Zeiss Axiovert 200 microscope equipped with a Coolsnap HQ Black and White camera of $1392 \times 1040$ resolution, and a 488$\mathrm{nm}$ laser. The temperature was maintained constant using a custom-built heating system. Eleven vertical sections spaced $0.5 \mu \mathrm{m}$ apart were taken every minute; maximal intensity projections of image stacks were produced using ImageJ software. Metamorph was also used for ring reconstructions and fluorescence intensity quantifications.

\section{Acknowledgments}

We are grateful to Elena Cano del Rosario for technical assistance. We are grateful to the ISREC-EPFL imaging facility for help with microscopy and to Juan-Carlos Sarriaz for assistance with image analysis. We thank Philippe Collin, Sandra Dischinger, Pierre Gönczy, Virginie Hachet, and Andrea Krapp for helpful discussions and critical reading of the manuscript. We thank Tom Pollard, Kathy Gould, Mohan Balasubramanian, and Iain Hagan for reagents. We are grateful to the Swiss National Science Foundation and EPFL for funding. O.H. is grateful to FEBS and HSFP for financial support.

\section{References}

Arai, R. and Mabuchi, I. 2002. F-actin ring formation and the role of F-actin cables in the fission yeast Schizosaccharomyces pombe. J. Cell Sci. 115: 887-898.

Bahler, J. and Pringle, J.R. 1998. Pom1p, a fission yeast protein kinase that provides positional information for both polarized growth and cytokinesis. Genes \& Dev. 12: 1356-1370.

Bahler, J., Steever, A.B., Wheatley, S., Wang, Y., Pringle, J.R., Gould, K.L., and McCollum, D. 1998. Role of polo kinase and Midlp in determining the site of cell division in fission yeast. J. Cell Biol. 143: 1603-1616.

Balasubramanian, M.K., Helfman, D.M., and Hemmingsen, S.M. 1992. A new tropomyosin essential for cytokinesis in the fission yeast $S$. pombe. Nature 360: 84-87.

Balasubramanian, M.K., McCollum, D., Chang, L., Wong, K.C., Naqvi, N.I., He, X., Sazer, S., and Gould, K.L. 1998. Isolation and characterization of new fission yeast cytokinesis mutants. Genetics 149: 1265-1275.

Bezanilla, M., Forsburg, S.L., and Pollard, T.D. 1997. Identification of a second myosin-II in Schizosaccharomyces pombe: Myp2p is conditionally required for cytokinesis. Mol. Biol. Cell 8: 2693-2705.

Bruno, K.S., Morrell, J.L., Hamer, J.E., and Staiger, C.J. 2001. $\mathrm{SEPH}$, a Cdc7p orthologue from Aspergillus nidulans, func- tions upstream of actin ring formation during cytokinesis. Mol. Microbiol. 42: 3-12.

Carnahan, R.H. and Gould, K.L. 2003. The PCH family protein, Cdc15p, recruits two F-actin nucleation pathways to coordinate cytokinetic actin ring formation in Schizosaccharomyces pombe. J. Cell Biol. 162: 851-862.

Celton-Morizur, S., Racine, V., Sibarita, J.B., and Paoletti, A. 2006. Pom 1 kinase links division plane position to cell polarity by regulating Mid1p cortical distribution. J. Cell Sci. 119: 4710-4718.

Cerutti, L. and Simanis, V. 1999. Asymmetry of the spindle pole bodies and spglp GAP segregation during mitosis in fission yeast. J. Cell Sci. 112: 2313-2321.

Chang, L. and Gould, K.L. 2000. Sid4p is required to localize components of the septation initiation pathway to the spindle pole body in fission yeast. Proc. Nat1. Acad. Sci. 97: 5249-5254.

Chang, F., Woollard, A., and Nurse, P. 1996. Isolation and characterization of fission yeast mutants defective in the assembly and placement of the contractile actin ring. I. Cell Sci. 109: 131-142.

Chang, F., Drubin, D., and Nurse, P. 1997. cdc12p, a protein required for cytokinesis in fission yeast, is a component of the cell division ring and interacts with profilin. J. Cell Biol. 137: 169-182.

Chitu, V., Pixley, F.J., Macaluso, F., Larson, D.R., Condeelis, J., Yeung, Y.G., and Stanley, E.R. 2005. The PCH family member MAYP/PSTPIP2 directly regulates F-actin bundling and enhances filopodia formation and motility in macrophages. Mol. Biol. Cell 16: 2947-2959.

Clifford, D.M., Wolfe, B.A., Roberts-Galbraith, R.H., McDonald, W.H., Yates III, J.R., and Gould, K.L. 2008. The Clp1/ Cdc14 phosphatase contributes to the robustness of cytokinesis by association with anillin-related Mid1. J. Cell Biol. 181: 79-88.

Daga, R.R. and Chang, F. 2005. Dynamic positioning of the fission yeast cell division plane. Proc. Natl. Acad. Sci. 102: 8228-8232.

Eng, K., Naqvi, N.I., Wong, K.C., and Balasubramanian, M.K. 1998. Rng2p, a protein required for cytokinesis in fission yeast, is a component of the actomyosin ring and the spindle pole body. Curr. Biol. 8: 611-621.

Fankhauser, C. and Simanis, V. 1994. The cdc7 protein kinase is a dosage dependent regulator of septum formation in fission yeast. $E M B O ~ J$. 13: 3011-3019.

Fankhauser, C., Marks, J., Reymond, A., and Simanis, V. 1993. The $S$. pombe cdc16 gene is required both for maintenance of p34cdc2 kinase activity and regulation of septum formation: A link between mitosis and cytokinesis? EMBO J. 12: 26972704.

Fankhauser, C., Reymond, A., Cerutti, L., Utzig, S., Hofmann, K., and Simanis, V. 1995. The S. pombe cdc15 gene is a key element in the reorganization of F-actin at mitosis. Cell 82: 435-444.

Furge, K.A., Wong, K., Armstrong, J., Balasubramanian, M., and Albright, C.F. 1998. Byr4 and Cdc16 form a two-component GTPase-activating protein for the Spg1 GTPase that controls septation in fission yeast. Curr. Biol. 8: 947-954.

Gould, K.L. and Simanis, V. 1997. The control of septum formation in fission yeast. Genes \& Dev. 11: 2939-2951.

Guertin, D.A., Chang, L., Irshad, F., Gould, K.L., and McCollum, D. 2000. The role of the sidlp kinase and cdc14p in regulating the onset of cytokinesis in fission yeast. $E M B O T$. 19: $1803-1815$.

Heitz, M.J., Petersen, J., Valovin, S., and Hagan, I.M. 2001. MTOC formation during mitotic exit in fission yeast. J. Cell Sci. 114: 4521-4532. 
Hou, M.C., Salek, J., and McCollum, D. 2000. Moblp interacts with the Sid2p kinase and is required for cytokinesis in fission yeast. Curr. Biol. 10: 619-622.

Jin, Q.W., Zhou, M., Bimbo, A., Balasubramanian, M.K., and McCollum, D. 2006. A role for the septation initiation network in septum assembly revealed by genetic analysis of sid2-250 suppressors. Genetics 172: 2101-2112.

Kamasaki, T., Osumi, M., and Mabuchi, I. 2007. Three-dimensional arrangement of F-actin in the contractile ring of fission yeast. J. Cell Biol. 178: 765-771.

Kitayama, C., Sugimoto, A., and Yamamoto, M. 1997. Type II myosin heavy chain encoded by the myo2 gene composes the contractile ring during cytokinesis in Schizosaccharomyces pombe. J. Cell Biol. 137: 1309-1319.

Krapp, A., Schmidt, S., Cano, E., and Simanis, V. 2001. S. pombe cdc1lp, together with sid4p, provides an anchor for septation initiation network proteins on the spindle pole body. Curr. Biol. 11: 1559-1568.

Krapp, A., Gulli, M.P., and Simanis, V. 2004. SIN and the art of splitting the fission yeast cell. Curr. Biol. 14: R722-R730. doi: 10.1016/j.cub.2004.08.049.

Le Goff, X., Woollard, A., and Simanis, V. 1999. Analysis of the cps1 gene provides evidence for a septation checkpoint in Schizosaccharomyces pombe. Mol. Gen. Genet. 262: 163-172.

Le Goff, X., Motegi, F., Salimova, E., Mabuchi, I., and Simanis, V. 2000. The $S$. pombe rlc1 gene encodes a putative myosin regulatory light chain that binds the type II myosins myo3p and myo2p. J. Cell Sci. 113: 4157-4163.

Liu, J., Wang, H., McCollum, D., and Balasubramanian, M.K. 1999. Drclp/Cpslp, a 1,3- $\beta$-glucan synthase subunit, is essential for division septum assembly in Schizosaccharomyces pombe. Genetics 153: 1193-1203.

MacIver, F.H., Glover, D.M., and Hagan, I.M. 2003a. A 'marker switch' approach for targeted mutagenesis of genes in Schizosaccharomyces pombe. Yeast 20: 587-594.

MacIver, F.H., Tanaka, K., Robertson, A.M., and Hagan, I.M. 2003b. Physical and functional interactions between polo kinase and the spindle pole component Cut12 regulate mitotic commitment in S. pombe. Genes \& Dev. 17: 1507-1523.

Marks, J., Hagan, I.M., and Hyams, J.S. 1986. Growth polarity and cytokinesis in fission yeast: The role of the cytoskeleton. J. Cell Sci. Suppl. 5: 229-241.

McCollum, D., Balasubramanian, M.K., Pelcher, L.E., Hemmingsen, S.M., and Gould, K.L. 1995. Schizosaccharomyces pombe $\mathrm{cdc} 4^{+}$gene encodes a novel EF-hand protein essential for cytokinesis. J. Cell Biol. 130: 651-660.

Minet, M., Nurse, P., Thuriaux, P., and Mitchison, J.M. 1979. Uncontrolled septation in a cell division cycle mutant of the fission yeast Schizosaccharomyces pombe. J. Bacteriol. 137: 440-446.

Mishra, M. and Oliferenko, S. 2008. Cytokinesis: Catch and drag. Curr. Biol. 18: R247-R250. doi: 10.1016/j.cub.2008. 01.029.

Mishra, M., Karagiannis, J., Trautmann, S., Wang, H., McCollum, D., and Balasubramanian, M.K. 2004. The Clp1p/Flp1p phosphatase ensures completion of cytokinesis in response to minor perturbation of the cell division machinery in Schizosaccharomyces pombe. J. Cell Sci. 117: 3897-3910.

Moreno, S., Klar, A., and Nurse, P. 1991. Molecular genetic analysis of fission yeast Schizosaccharomyces pombe. Methods Enzymol. 194: 795-823.

Motegi, F., Mishra, M., Balasubramanian, M.K., and Mabuchi, I. 2004. Myosin-II reorganization during mitosis is controlled temporally by its dephosphorylation and spatially by Mid1 in fission yeast. J. Cell Biol. 165: 685-695.

Ohkura, H., Hagan, I.M., and Glover, D.M. 1995. The conserved Schizosaccharomyces pombe kinase plo1, required to form a bipolar spindle, the actin ring, and septum, can drive septum formation in G1 and G2 cells. Genes \& Dev. 9: 1059-1073.

Padte, N.N., Martin, S.G., Howard, M., and Chang, F. 2006. The cell-end factor pom $1 p$ inhibits midlp in specification of the cell division plane in fission yeast. Curr. Biol. 16: 2480-2487.

Paoletti, A. and Chang, F. 2000. Analysis of mid1p, a protein required for placement of the cell division site, reveals a link between the nucleus and the cell surface in fission yeast. Mol. Biol. Cell 11: 2757-2773.

Petronczki, M., Lenart, P., and Peters, J.M. 2008. Polo on the rise-From mitotic entry to cytokinesis with Plk1. Dev. Cell 14: 646-659.

Rosenberg, J.A., Tomlin, G.C., McDonald, W.H., Snydsman, B.E., Muller, E.G., Yates III, J.R., and Gould, K.L. 2006. Ppc89 links multiple proteins, including the septation initiation network, to the core of the fission yeast spindle-pole body. Mol. Biol. Cell 17: 3793-3805.

Schmidt, S., Sohrmann, M., Hofmann, K., Woollard, A., and Simanis, V. 1997. The Spg1p GTPase is an essential, dosagedependent inducer of septum formation in Schizosaccharomyces pombe. Genes \& Dev. 11: 1519-1534.

Simanis, V. 2003. Events at the end of mitosis in the budding and fission yeasts. J. Cell Sci. 116: 4263-4275.

Sohrmann, M., Fankhauser, C., Brodbeck, C., and Simanis, V. 1996. The $d \mathrm{mf1} / \mathrm{mid} 1$ gene is essential for correct positioning of the division septum in fission yeast. Genes \& Dev. 10: 2707-2719.

Sohrmann, M., Schmidt, S., Hagan, I., and Simanis, V. 1998. Asymmetric segregation on spindle poles of the Schizosaccharomyces pombe septum-inducing protein kinase Cdc $7 \mathrm{p}$. Genes \& Dev. 12: 84-94.

Sparks, C.A., Morphew, M., and McCollum, D. 1999. Sid2p, a spindle pole body kinase that regulates the onset of cytokinesis. J. Cell Biol. 146: 777-790.

Spencer, S., Dowbenko, D., Cheng, J., Li, W., Brush, J., Utzig, S., Simanis, V., and Lasky, L.A. 1997. PSTPIP: A tyrosine phosphorylated cleavage furrow-associated protein that is a substrate for a PEST tyrosine phosphatase. J. Cell Biol. 138: 845-860.

Tanaka, K., Petersen, J., MacIver, F., Mulvihill, D.P., Glover, D.M., and Hagan, I.M. 2001. The role of Plol kinase in mitotic commitment and septation in Schizosaccharomyces pombe. EMBO J. 20: 1259-1270.

Tomlin, G.C., Morrell, J.L., and Gould, K.L. 2002. The spindle pole body protein Cdc1lp links Sid4p to the fission yeast septation initiation network. Mol. Biol. Cell 13: 1203-1214.

Vavylonis, D., Wu, J.Q., Hao, S., O'Shaughnessy, B., and Pollard, T.D. 2008. Assembly mechanism of the contractile ring for cytokinesis by fission yeast. Science 319: 97-100.

Wachtler, V., Huang, Y., Karagiannis, J., and Balasubramanian, M.K. 2006. Cell cycle-dependent roles for the FCH-domain protein Cdc15p in formation of the actomyosin ring in Schizosaccharomyces pombe. Mol. Biol. Cell 17: 3254-3266.

Wolfe, B.A. and Gould, K.L. 2005. Split decisions: Coordinating cytokinesis in yeast. Trends Cell Biol. 15: 10-18.

Wu, J.Q., Bahler, J., and Pringle, J.R. 2001. Roles of a fimbrin and an $\alpha$-actinin-like protein in fission yeast cell polarization and cytokinesis. Mol. Biol. Cell 12: 1061-1077.

Wu, J.Q., Kuhn, J.R., Kovar, D.R., and Pollard, T.D. 2003. Spatial and temporal pathway for assembly and constriction of the contractile ring in fission yeast cytokinesis. Dev. Cell 5: 723-734.

Wu, J.Q., Sirotkin, V., Kovar, D.R., Lord, M., Beltzner, C.C., Kuhn, J.R., and Pollard, T.D. 2006. Assembly of the cytokinetic contractile ring from a broad band of nodes in fission yeast. J. Cell Biol. 174: 391-402. 


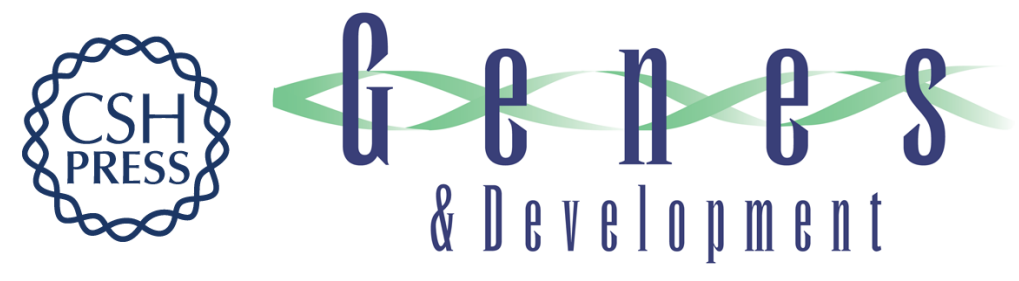

\section{Mid1p/anillin and the septation initiation network orchestrate contractile ring assembly for cytokinesis}

Olivier Hachet and Viesturs Simanis

Genes Dev. 2008, 22:

Access the most recent version at doi:10.1101/gad.1697208

\section{Supplemental http://genesdev.cshlp.org/content/suppl/2008/11/24/22.22.3205.DC1 Material}

Related Content

Stepping into the ring: the SIN takes on contractile ring assembly Rachel H. Roberts-Galbraith and Kathleen L. Gould

Genes Dev. November , 2008 22: 3082-3088

References This article cites 61 articles, 41 of which can be accessed free at: http://genesdev.cshlp.org/content/22/22/3205.full.html\#ref-list-1

Articles cited in:

http://genesdev.cshlp.org/content/22/22/3205.full.html\#related-urls

\section{License}

Email Alerting

Service

Receive free email alerts when new articles cite this article - sign up in the box at the top right corner of the article or click here.

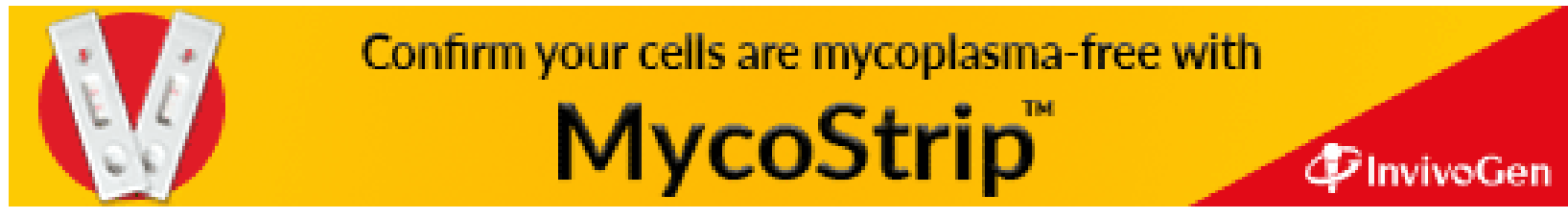

